With 3 plates

Printed in Great Britain

\title{
Studies on Filamentous Forms of Bacillus cereus strain $\mathbf{T}$
}

\author{
By ANN WAHREN, T. HOLME AND ANNA HÄGGMARK \\ Department of Bacteriology, Karolinska Institutet, Stockholm, Sweden \\ AND P.-G. LUNDQUIST \\ King Gustaf $V$ Research Institute Stockholm, Sweden
}

(Accepted for publication 8 April 1967)

\begin{abstract}
S U M MAR Y
A mutant growing as long filaments was regularly observed in continuous cultures of Bacillus cereus strain T. The filaments had approximately the same diameter as the parent bacilli and septa were observed at regular intervals, corresponding to the length of single bacilli of the parental type. The links between the individual organisms in the filaments appeared to possess high mechanical strength, as shown by their resistance to ultrasonic treatment. Lysozyme treatment resulted in a complete fragmentation of the filaments into bacilli of the same size as single normal organisms. Electron microscopy showed that the septa of the filaments were thinner than those displayed by dividing normal organisms. A zone of lower electron density, which developed in the contact zones between dividing normal bacilli in the early stages of division, was not observed in the links between the filamentous bacilli.
\end{abstract}

\section{INTRODUCTION}

Several observations have been reported on the formation of filaments from many different bacteria under the influence of, for example, penicillin, magnesium starvation and growth at elevated temperatures. As pointed out by Hughes (1956) these filaments are formed in response to adverse growth conditions and they give rise to organisms of normal appearance when ordinary conditions for growth are restored. The occurrence of a stable filamentous variant of Bacillus megaterium was, however, reported by Shaforostova (1962). This variant was obtained in continuous culture and could be maintained through several transfers on nutrient agar. It replaced the normal bacilli at high dilution rates and created a flocculent growth in the culture vessel. It was asporogenous, and no septa were detected in the filaments by using phase-contrast microscopy.

In the present investigation a stable filamentous variant was produced by continuous cultivation of Bacillus cereus $\mathbf{T}$ and a comparative study of some characteristics of normal and filamentous organisms was made.

\section{METHODS}

Cultivation methods. Nutrient agar (Difco) was used for maintenance of the bacterial strains and for the study of colonial morphology. Liquid cultures were grown in indented Erlenmeyer flasks on a rotary shaker. The incubation temperature was $30^{\circ}$. The media used were nutrient broth (Difco) and a minimal medium of the following 
composition (g./l.): glucose, IO; $\left(\mathrm{NH}_{4}\right)_{2} \mathrm{SO}_{4}, \mathrm{I} ; \mathrm{KH}_{2} \mathrm{PO}_{4}, 3 ; \mathrm{K}_{2} \mathrm{HPO}_{4}, 7 ; \mathrm{MgSO}_{4} \cdot 7 \mathrm{H}_{2} \mathrm{O}$ $0.2 ; 0.5 \mathrm{ml}$. of a trace elements solution of the following composition (g./1.): $\mathrm{CaCl}_{2}, \mathrm{I}$; $\mathrm{FeCl}_{3} \cdot 6 \mathrm{H}_{2} \mathrm{O}, 33 ; \mathrm{ZnSO}_{4} \cdot 7 \mathrm{H}_{2} \mathrm{O}, 0 \cdot 36 ; \mathrm{CuSO}_{4} \cdot 5 \mathrm{H}_{2} \mathrm{O}, 0.32 ; \mathrm{CoCl}_{2} \cdot 6 \mathrm{H}_{2} \mathrm{O}, 0 \cdot 37$. Turbidity measurements were made in a Bausch and Lomb colorimeter. Dry weights were determined in duplicate on $20 \mathrm{ml}$. samples by centrifuging the organisms at $5000 \mathrm{~g}$ for $20 \mathrm{~min}$., washing in $0.01 \mathrm{M}$-phosphate buffer ( $\mathrm{pH}_{7}$ ) and drying to constant weight at $100^{\circ}$. The morphology of the organisms was examined by phase-contrast microscopy.

Chemical methods. Glucose was determined enzymically (Levin \& Linde, 1962). Pyruvate analysis was done according to Friedemann \& Haugen (1943) and lactate analysis according to Barker \& Summerson (194I). Poly- $\beta$-hydroxybutyrate was determined gravimetrically as follows. The organisms were treated with sodium hypochlorite (commercial solution, approximately $12 \%$ active chlorine) followed by washings of the liberated granules in distilled water, acetone, ethanol and diethylether and extraction in boiling chloroform (Williamson \& Wilkinson, 1958, Law \& Slepecky, I96r). The solution was filtered, the chloroform evaporated and the remaining material was weighed.

Cell walls were prepared by disintegration of the organisms in a freeze press (Edebo, I960) followed by differential centrifugation (Salton, 1964). The cell-wall preparations were washed three times in $0.1 \mathrm{M}$-citrate phosphate buffer $\left(\mathrm{pH}_{7}\right)$ and three times in M-sodium chloride. Poly- $\beta$-hydroxybutyrate was removed from the cell walls by treatment with chloroform. Analysis of amino acids and amino sugars was done by thin layer chromatography according to Stahl (1962). Extracellular polysaccharides were extracted (Wilkinson, 1958) and analysed according to Snell \& Snell (1953).

Electron microscopy. Preparations for electron microscopy were made according to Ryter \& Kellenberger (1958) and Murray, Steed \& Elson (1965). The bacteria used were grown on nutrient agar for $10 \mathrm{hr}$. Dehydration and embedding in epon was done according to Lundquist (1965). All specimens were stained with uranyl acetate (Watson, 1958) and lead acetate (Karnovsky, 196I).

\section{RESULTS}

\section{Morphology}

The colonies of the filamentous forms did not show any detectable difference from those of the normal bacilli. Under the microscope, however, the filamentous forms displayed a mycelial appearance. The filaments usually had a length corresponding to more than 100 normal bacilli. The filaments had approximately the same diameter as the normal bacilli and septa were observed at regular intervals, corresponding roughly to the length of normal cells (Pl. I, figs I, 2; Pl. 3, fig. 7).

\section{Cultivation experiments}

The appearance of the filamentous variant in the microscope was very characteristic. To ascertain its purity serial transfers were made from the original isolate by picking one colony onto nutrient agar medium. During a continued serial transfer with 2-day intervals for 2 months no difference in the morphology of the organisms was observed. Normal bacilli were grown in parallel under the same conditions and they also retained their microscopical appearance.

No differences in nutrient requirements or growth rate in liquid media were detected 
during experiments with minimal medium and nutrient broth. The filamentous forms sporulated readily after incubation for 2 days at $30^{\circ}$ on nutrient agar. A spore suspension prepared from the outgrowth of filamentous forms was heated to $80^{\circ}$ for $30 \mathrm{~min}$. and then plated on nutrient agar. The resulting colonies consisted of filamentous forms. Normal bacilli subjected to the same treatment also retained their morphology.

\section{Metabolism}

Normal and filamentous organisms were grown in the minimal medium with the addition of Casamino Acids (Difco) $5 \mathrm{~g}$. and sodium acetate $2 \mathrm{~g}$./1.; glucose concentration $2 \mathrm{~g}$./l. The cultures were inoculated with organisms from a culture which had

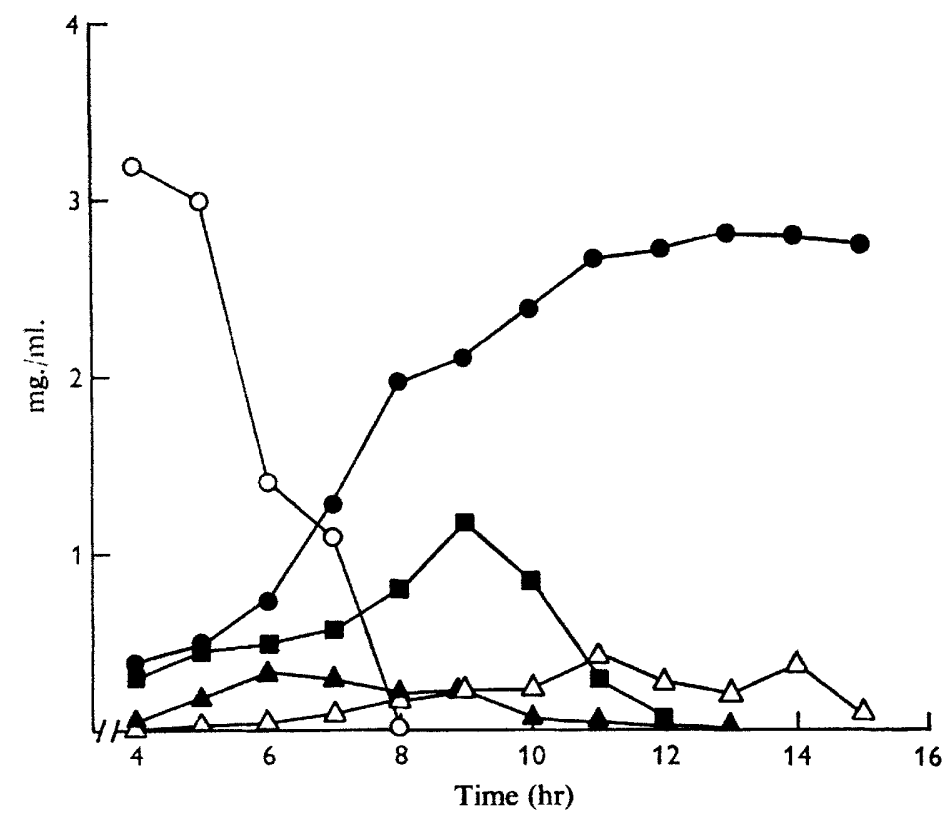

Fig. 1. Some metabolic properties of normal bacilli of Bacillus cereus $\mathrm{T}$. The curves illustrate glucose utilization, lactate and pyruvate formation and poly- $\beta$-hydroxybutyrate accumulation during growth. Dry weight, -0 ; glucose, $O-0$; lactate, $\mathbf{\square - \mathbf { B }}$; pyruvate, $\boldsymbol{\Delta}-\boldsymbol{\Delta}$; poly- $\beta$-hydroxybutyrate, $\triangle-\triangle$.

grown for $10 \mathrm{hr}$. The growth curves, the analytical data on poly- $\beta$-hydroxybutyric acid accumulation, the formation of lactate and pyruvate and the utilization of glucose did not show any significant differences between the two morphological forms (Figs 1, 2).

\section{Lysozyme treatment}

Normal organisms of Bacillus cereus $\mathrm{T}$ are highly resistant to lysozyme, no protoplasts appearing under appropriate conditions even after prolonged incubation with the enzyme (Salton \& Pavlik, I960). However, organisms in the early logarithmic phase, showing short chains, were rapidly fragmented into separate rods when lysozyme was added. In one experiment with normal and filamentous forms, organisms were grown in minimal medium and harvested in the late log phase. Here normal bacilli occurred separately. Both forms were suspended in $0.01 \mathrm{M}$-phosphate buffer 
( $\mathrm{pH} 7$ ) containing $0.5 \mathrm{M}$-sucrose. The suspensions were divided in two portions: to one portion of each suspension lysozyme was added to $2 \mathrm{mg} . / \mathrm{ml}$.; the other portion served as a control. After treatment for $30 \mathrm{~min}$. at room temperature the filaments began to fragment into rods corresponding in length to the normal bacilli and after $2 \mathrm{hr}$ no filaments were seen. No effect of the lysozyme treatment on the normal bacilli was noted and no morphological change occurred in the controls during the experimental period. The bacilli resulting from the lysozyme-treated filaments were viable, as shown by spreading them on nutrient agar; after incubation for $36 \mathrm{hr}$ at $30^{\circ}$ colonies were formed which showed only filamentous forms when examined microscopically.



Fig. 2. Some metabolic properties of the filamentous forms of Bacillus cereus $\mathrm{r}$. For symbols, see fig. $\mathrm{I}$.

\section{Ultrasonic treatment}

Ultrasonic disintegration was applied to preparations of both morphological forms in order to compare cell-wall fragments under the microscope. Normal bacilli and filamentous forms grown on nutrient agar for $10 \mathrm{hr}$ were suspended in $0.0 \mathrm{r}$ M-phosphate buffer ( $\mathrm{pH} 7$ ). The suspensions were treated in a MSE sonic disintegrator at maximum efficiency for $30 \mathrm{sec}$. and then examined by phase-contrast microscopy. In Pl. I, fig. 3, the appearance of disintegrated normal bacilli is shown; most of the fragments consist of halved cell walls. In Pl. I, fig. 4, disintegrated filamentous forms are shown; most of the fragments consist of two cell-wall halves connected by a septum showing the mechanical strength of the links between the cells.

\section{Chemical composition of cell walls}

Cell-wall preparations from normal bacilli and from filamentous forms were hydrolysed in $6 \mathrm{M}$-hydrochloric acid for $12 \mathrm{hr}$ at $105^{\circ}$ in sealed tubes. Thin-layer chromatography on the hydrolysate showed the presence of the following substances: alanine, 
$\alpha$ - $\varepsilon$-diaminopimelic acid, glutamic acid, glucosamine, galactosamine. One unidentified rapidly migrating substance was also detected. No difference in the cell-wall composition with regard to amino acids and amino sugars was found by this method. Since the size and colour intensity of the spots from chromatograms from the two morphological forms did not indicate any major quantitative differences no attempt to elaborate a quantitative analysis was made.

\section{Electron microscopy}

The normal bacilli were characterized by rounded ends and contact zones of varying breadth (Pl. 2, fig. 5). Sometimes the bacilli occurred in short chains; these chains regularly consisted of pairs of rods with a septum, each pair separated from the next by a small contact zone. Each bacillus displayed a cell wall of normal thickness in the contact zone, the two bacilli being separated by an area of lower electron density (Pl. 2, fig. 6). The thickness of these contact zones was approximately $700 \AA$. The cytoplasmic membrane was clearly visible immediately inside the cell wall. Most of the contact zones in the filamentous forms were characteristically thinner than those displayed by dividing normal bacilli being approximately $400 \AA$. When present, the constriction around this contact zone was very small. The distinct area of lower electron density in the contact zone of normal bacilli was absent (P1. 3, figs 7, 8). No further differences with regard to thickness or appearance of the cell walls of the normal and filamentous forms was observed.

\section{DISCUSSION}

Most of the filamentous forms of Bacillus cereus described in the literature (Kominek \& Halvorson, 1965; Hughes, 1956) have been the result of a phenotypic variation. The filamentous variant isolated from continuous cultures of $B$. cereus $\mathrm{T}$ described here showed a great genetic stability. Spores, isolated from the filamentous forms, gave rise only to filamentous forms upon germination. Lysozyme treatment resulted in a fragmentation of the filaments into rods of the same appearance as normal bacilli. These rods were viable and yielded filamentous forms when grown on nutrient agar. The two morphological forms did not differ significantly in their growth patterns or in the gross chemical composition of their cell walls. However, during the purification procedure accessory cell-wall components (Stolp \& Starr, 1965) may have been lost; these are mainly polysaccharides and mucopolysaccharides in Gram-positive organisms. It is possible that there are certain differences in the accessory components even if the 'murein sacculus' (Weidel \& Pelzer, 1964) appears to be of the same chemical composition in the two forms. Attempts to isolate polysaccharides from whole organisms by mild extraction procedures gave negative results, however, which makes it less probable that the difference between the two forms is a difference in the cell-wall polysaccharides.

In the electron microscope the links between cells in the filaments did not show a distinct zone of lower electron density, as was clearly observed in dividing normal forms, which thus indicated a separation into two distinct cell walls. The links between the cells in the filaments were of approximately the same thickness as the cell wall proper. The results of the ultrasonic treatment indicated a high mechanical resistance of theselinks. They were, however, sensitive to lysozyme. It is known that the lysozymesensitive $\beta$-I-4-glucosidic bond between glucosamine and muramic acid is of great 
importance to the stability of the cell wall. The reason for the resistance of many bacterial cells to lysozyme is not known, but is usually ascribed to a masking effect of accessory components of the wall. A tentative interpretation of the present results would be that the filamentous forms lack the ability to split bonds in the septa which separate the cells and thereby to complete division. These bonds appear to be lysozymesensitive and contribute to a high mechanical strength of the septa.

\section{REFERENCES}

BARKER, S. B. \& SUMmerson, W. H. (194I). The colorimetric determination of lactic acid in biological material. J. biol. Chem. 138, 535 .

EDEBO, L. (1960). A new press for disruption of micro-organisms and other cells. J. biochem. microbiol. Technol. Engng 2, 453.

Friedemann, T. E. \& Haugen, G. (1943). Pyruvic acid. II. Determination of keto acids in blood and urine. J. biol. Chem. 147, 415 .

Hughes, W. H. (1956). The structure and development of the induced long forms of bacteria. Symp. Soc. gen. Microbiol. 6, 34I.

KARNovsKY, M. J. (196I). Simple methods for 'staining with lead' at high pH in electron microscopy. J. biophys, biochem. Cytol. I1, 729.

Kominek, L. A. \& Halvorson, H. O. (1965). Metabolism of poly- $\beta$-hydroxy-butyrate and acetoin in Bacillus cereus. J. Bact. 90, $125 \mathrm{I}$.

LAW, J. H. \& SLEPECKY, R. A. (196I). Assay of poly- $\beta$-hydroxybutyric acid. J. Bact. 82, 33.

LEVIN, K. \& LINDE, S. (1962). Bestämning av glykos i blod, liquor och urin med ett nytt glykosoxidasreagens. Svenska Läkartidn. 59, 3016.

Lundouist, P.-G. (1965). The endolymphatic duct and sac in the guinea pig. An electron microscopic and experimental investigation. Acta Oto-lar. Suppl. 201, 16.

Murray, R. G. E., Steed, P. \& Elson, H. E. (I965). The location of the mucopeptide in sections of the cell wall of $E$. coli and other Gram-negative bacteria. Can. J. Microbiol. II, 547.

Ryter, A. \& Kellenberger, E. (1958). Etude au microscope electronique de plasmas contenant de l'acide désoxyribonucleique. I. Les nucléotides des bactéries en croissance active. $Z$. Naturf. r3 $b, 597$.

Salton, M. R. J. (1964). The Bacterial Cell Wall. Amsterdam: Elsevier.

Salton, M. R. J. \& Pavlik, J. G. (1960). Studies of the bacterial cell wall. VI. Wall composition and sensitivity to lysozyme. Biochim. biophys. Acta 39, 398.

Shaforostova, L. D. (1962). Dissociation of Bacillus megaterium in flow culture. Microbiology 3I, 531 .

Snell, F. D. \& Snell, C. T. (1953). Colorimetric Methods of Analysis, Vol. III. New York: van Nostrand Co.

STAHL, E. (1962). Dünnschichtchromatographie. Berlin: Springer Verlag.

Stolp, H. \& StarR, M. P. (1965). Bacteriolysis. A. Rev. Microbiol. 19, 79.

Watson, M. L. (1958). Staining of tissue sections for electron microscopy with heavy metals. $J$. biophys. biochem. Cytol. 4, 475.

WeIDel, W. \& Pelzer, H. (I964). Bagshaped macromolecules-a new outlook on bacterial cell walls. Adv. Enzymol. 26, 193.

Wilknnson, J. F. (1958). The extracellular polysaccharides of bacteria. Bact. Rev. $22,46$.

Williamson, D. H. \& Wilkinson, J. F. (1958). The isolation and estimation of the poly- $\beta$-hydroxybutyrate inclusions of Bacillus species. J. gen. Microbiol. 19, 198. 

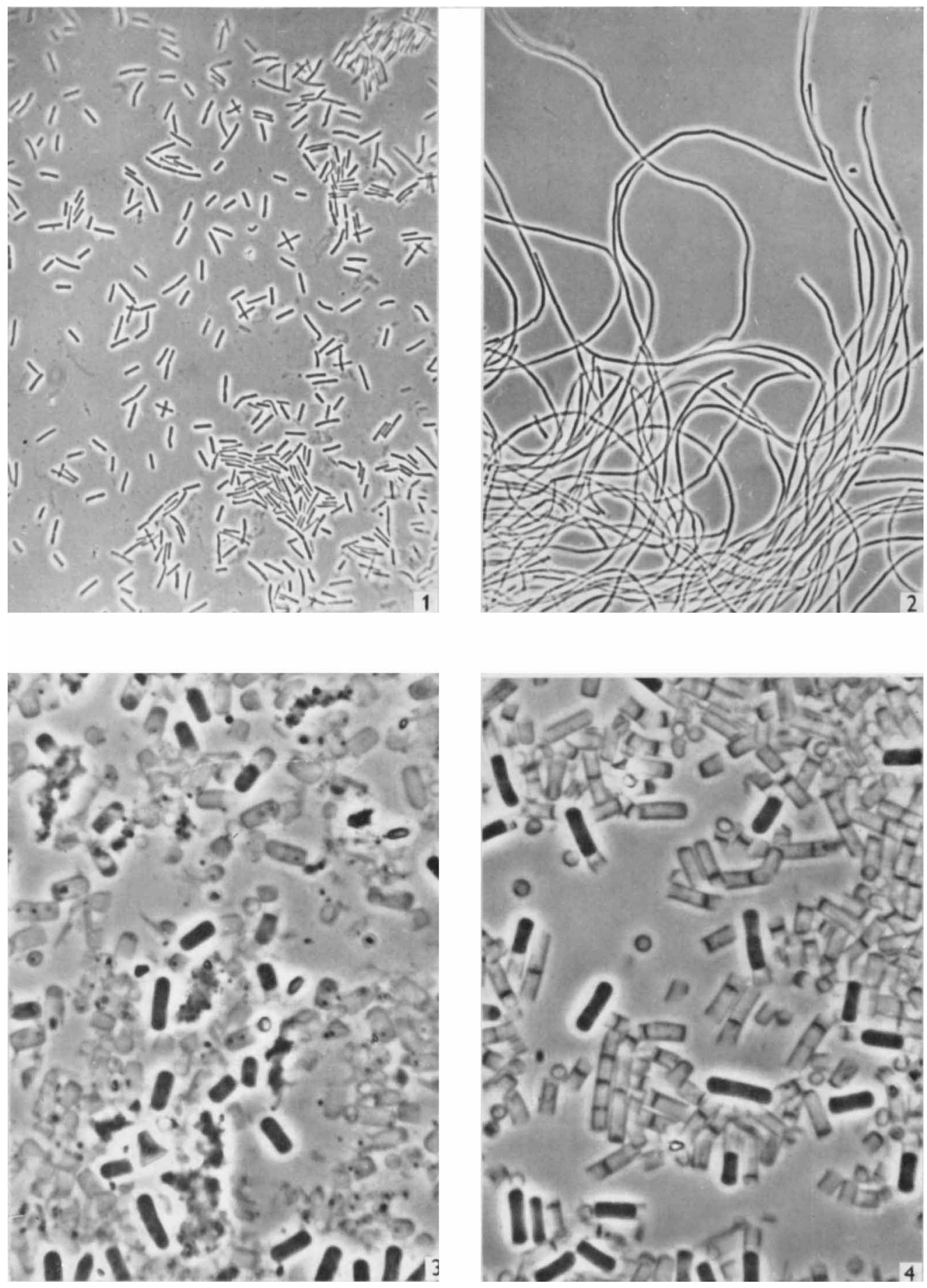

A. WAHREN, T. HOLME, A. HÄGGMARK AND P.-G. LUNDQUIST

(Facing p. 64) 


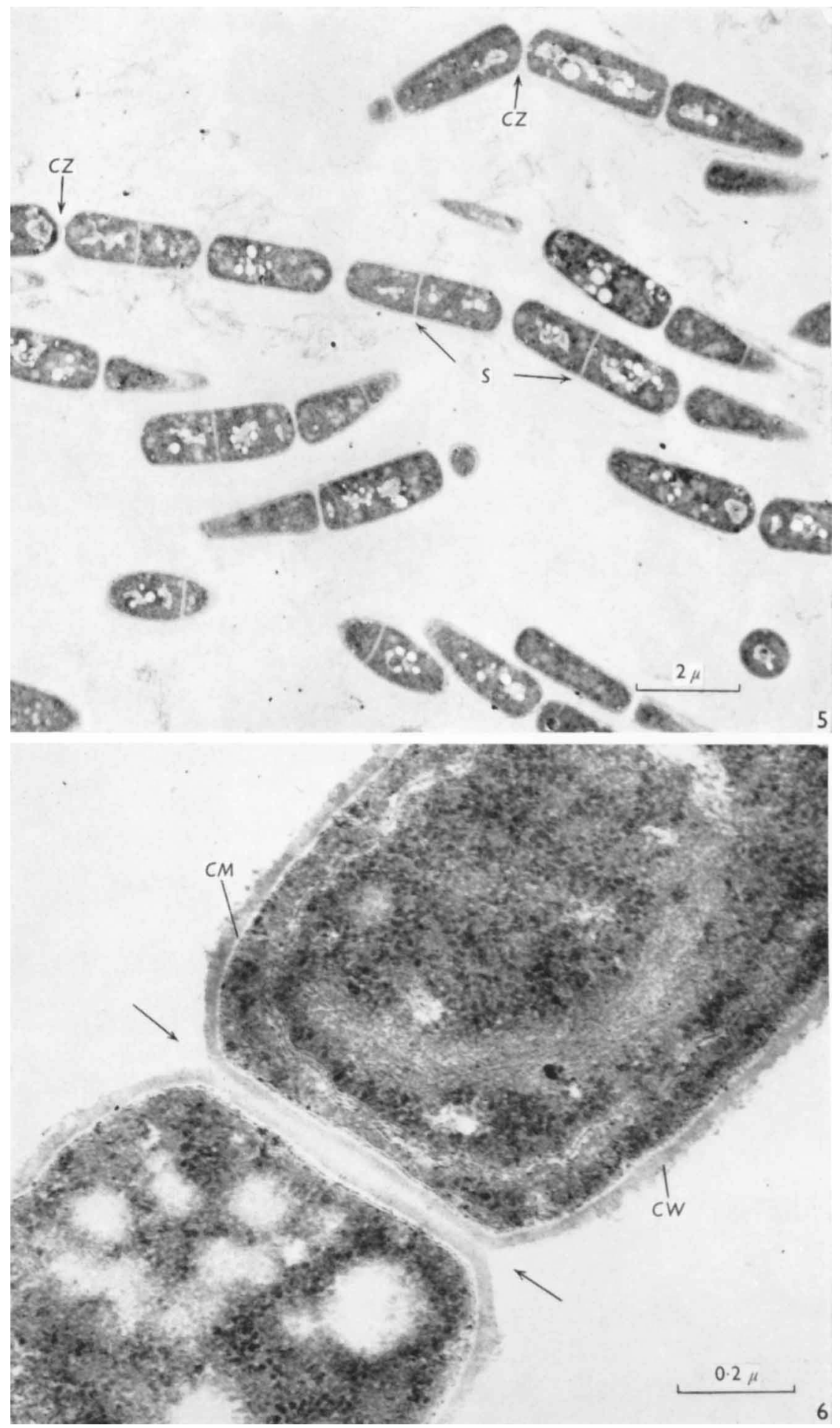

A. WAHREN, T. HOLME, A. HÄGGMARK AND P.-G. LUNDQUIST 
Journal of General Microbiology, Vol. 49, No. 1

Plate 3
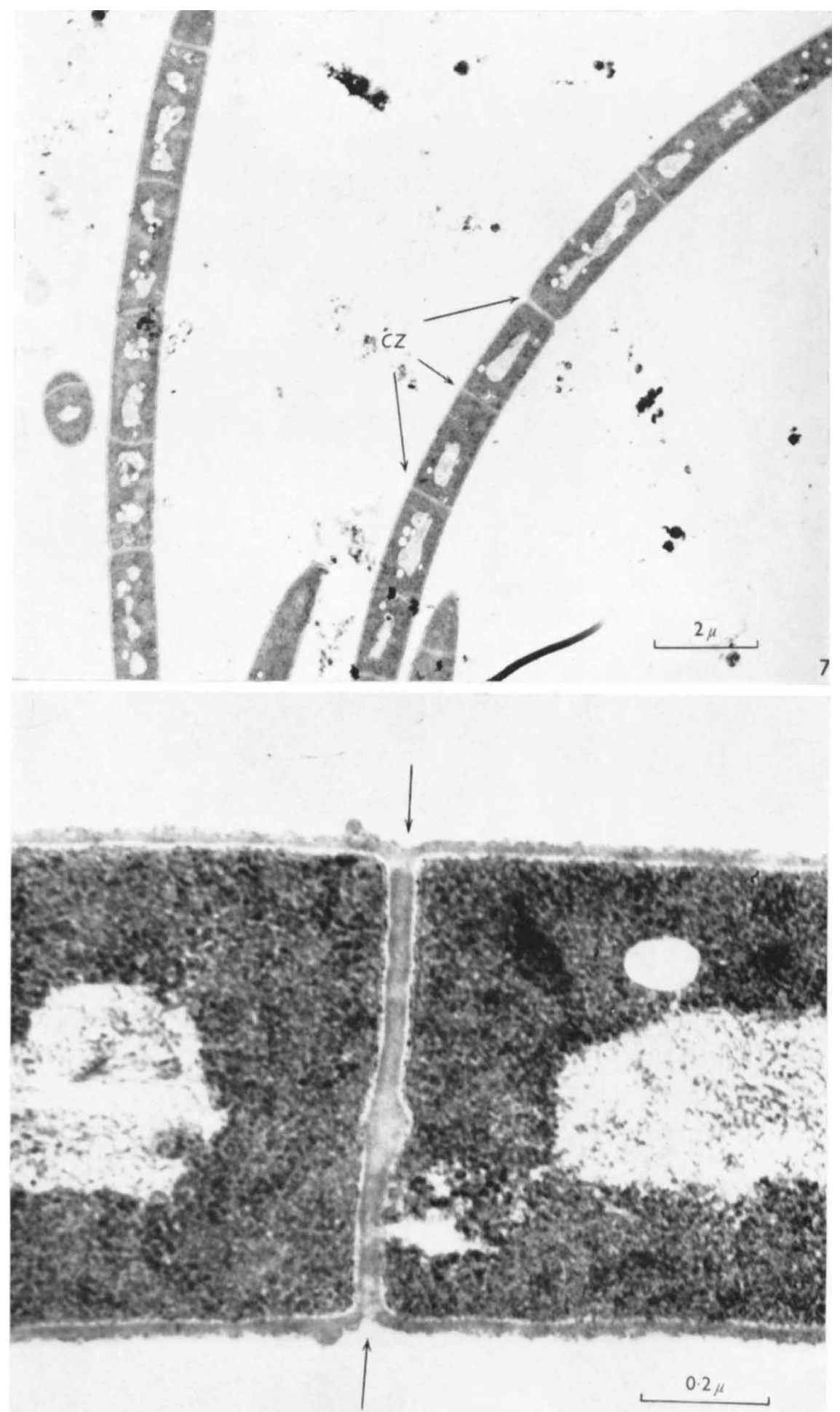


\section{EXPLANATION OF PLATES}

Plate 1

(Phase-contrast microscopy; figs. I, $2 \times 530$; figs. $3,4 \times 2100$ )

Fig. I. Normal bacilli of Bacillus cereus $\mathbf{T}$.

Fig. 2. Filamentous forms of $B$. cereus $\mathrm{T}$.

Fig. 3. Normal bacilli of $B$. cereus $\mathrm{T}$ after ultrasonic treatment.

Fig. 4. Filamentous forms of $B$. cereus $\mathrm{T}$ after ultrasonic treatment.

\section{Plate 2}

Fig. 5. Electron microscopic survey of normal bacilli of Bacillus cereus $\mathrm{T}$. The bacilli are arranged in pairs with a straight septum (S) between the two bacilli and the rounded free ends connected with adjacent pairs by a short wide contact zone (CZ). Many lightly stained poly- $\beta$-hydroxybutyrate granules can be seen in the cytoplasm. $(\times 9000$.)

Fig. 6. Detail of normal bacilli of Bacillus cereus $\mathrm{T}$ demonstrating the wide contact zone (700 $\AA$ ) between two pairs of bacilli (arrows). A zone of lower electron density than the normal cell wall is seen. Inside the cell wall $(\mathrm{CW})$ a cytoplasmic membrane $(\mathrm{CM})$ can be seen $(\times 100,000)$.

\section{Plate 3}

Fig. 7. Electron microscopic survey of filamentous forms of Bacillus cereus $\mathrm{T}$ demonstrating the straight contact zones $(\mathrm{CZ})(\times 9000)$.

Fig. 8. Detail of contact zone (arrows) of filamentous forms of Bacillus cereus $\mathrm{T}$ demonstrating the straight and narrow $(400 \AA)$ contact zone. The distinct zone of lower electron density of the contact zone, as found in the normal bacilli, is absent. The cell wall and cytoplasmic membrane exhibit an appearance similar to those of normal bacilli. Sometimes a slightly thickened area could be seen in the contact zone with a width of up to $700 \AA\left(\times{ }_{1}(0,000)\right.$. 